\title{
Designing for reportability: sustainable gamification, public engagement, and promoting environmental debate
}

\author{
Peter Tolmie • Alan Chamberlain · Steve Benford
}

Received: 4 September 2013/Accepted: 12 November 2013/Published online: 8 December 2013

(C) The Author(s) 2013. This article is published with open access at Springerlink.com

\begin{abstract}
There is a growing emphasis in many countries on matters such as participation in e-government, e-democracy, the provision of forums for online debate, and so on. A critical issue in all of these cases is one of encouraging engagement across a broad spectrum of potentially interested parties and stakeholders. In this paper, we use an ethnographic study of an online event, designed to encourage debate, to explore some critical issues in how the mechanisms productive of debate have shifted in company with the Web 2.0 phenomenon. By contrasting this with a prior study of how players managed their gameplay in a multiplayer pervasive game, we focus upon how different ways of constructing games and events can have serious implications for their ordinary everyday reportability in routine face-to-face interactions. We conclude that designing for reportability should be an active consideration when designing the resources for online debate and consider some ways in which that might be accomplished.
\end{abstract}

Keywords Ethnographic studies · e-Democracy · Online debate - Web 2.0 - Pervasive games . Reportability · Ethnomethodology

\footnotetext{
P. Tolmie $\cdot$ A. Chamberlain $(\bowtie) \cdot S$. Benford

Mixed Reality Lab, Computer Science, University

of Nottingham, Nottingham NG8 1BB, UK

e-mail: alan.chamberlain@nottingham.ac.uk

P. Tolmie

e-mail: Peter.tolmie@Nottingham.ac.uk

S. Benford

e-mail: Steve.benford@Nottingham.ac.uk
}

\section{Introduction}

One of the much-lauded potentialities of the Internet over recent years has been its capacity to foster greater public participation in government and the development of policy (see, for instance, [22, 36, 37]).

This is emphasised by a recent recommendation from a Committee of Ministers to the Council of Europe regarding e-democracy that recognises that

'...information and communication technology (ICT) is progressively facilitating the dissemination of information about, and discussion of, political issues, wider democratic participation by individuals and groups and greater transparency and accountability in democratic institutions and processes, and is serving citizens in ways that benefit democracy and society'.

[14]

There are a number of potential mechanisms that are currently being exploited to try and encourage this trend, including the creation of e-democracy portals [1, 33], involving people in the gathering, and electronic submission of data relating to current issues [17, 37], online consultation [46]; online deliberation [30]; e-voting [14]; Webcasts [18, 34], social networking sites [47], e-panels [34]; wikis [16], blogging [22], and so on.

However, in view of this push to online participation, it is becoming increasingly important to consider just how well it is providing for vital components of participation such as debate [39]. At present, a number of online forums for debate (or e-debate) have been developed [19, 20, 21, 41]. These forums work in a number of different ways, for instance through the provision of dedicated chat rooms [46]; the creation of dedicated sites to stimulate debate where people can create connected blogs, submit video 
clips, and other media (rather like YouTube) [21, 47]; the rating of different posts and online voting [20], viewing and responding to online newsletters [20], submitting short texts to political candidates and public figures that can be tagged and counted to push back to representatives current 'hot' issues [18], engaging in online community activities similar to social networking [26], and so on. Something to note about these various mechanisms is the extent to which they are structured around the notion of single individuals sat at computers browsing the Internet. This presumed mode of engagement reflects a much wider shift in how people consume media, which has moved away from multiparty, co-present, single point of contact consumption towards distributed single parties consuming different media simultaneously, from numerous different sources [5, $19,28,30,32,40]$. As a part of this broader trend, we can see how the technologies productive of debate have shifted. Whilst broadcast media continues to provide quality materials centred upon the debate of currently significant topics such as Question Time, Arena, and Crossfire, the consumption of such broadcasts has changed. Up until the advent of digital TV, on-demand viewing and iPlayer [27], YouTube, and a host of other related revolutions in video consumption, broadcasts productive of debate went out at a predictable scheduled time, to a relatively consistent segment of the population, who were largely clustered in single cohort groups (families, friends, etc.) around a single television. Debate frequently spilled out from the broadcast content to these co-present groups, facilitating active discussion and the formulation of opinion [33]. Echoes of these debates and further elaborations upon them often continued the following day amongst work cohorts, in discussions prefaced with phrases such as 'did you see Eastenders last night?' [8]. Of course, it is also important to recognise the role of other medias within this paradigm such as radio and print, and the pivotal role that these have played in the formation of both televisual and Web-based media for reporting. An important part of the argument surrounding e-democracy [29] is that the Web 2.0 revolution and the shift in the focus of debate to online resources such as blogs, online discussion groups and chat rooms, rating groups, YouTube, podcasts, and so on has facilitated greater access amongst a much wider cross section of the population to these kinds of resources [14]. This is undeniably the case. However, some studies have started to scope out the use of technology, crowd-sourcing, and ecology [9], although these deal with an expert user and are highly site-specific, whilst other public ubiquitous computing experiences have been artistic interventions that have run over a short period of time, with a self-selecting audience [12].

As we begin to demonstrate in this paper, this revolution can also serve to fragment and isolate consumption in ways that can undermine active co-present discussion amongst specific cohorts and, whilst serving to inform particular individuals, render issues invisible to the other people who are around them. Indeed, some recent research seems to indicate that it is exactly the involvement of Internet users in online groups and social networking services that have had the most impact upon TV consumption [40].

In this paper, we use an ethnographic study of an online event designed to prompt debate about environmental issues to delineate some of the problems outlined above before moving on to a discussion of how it might be possible to bridge the two worlds of online and co-present debate, enabling the richness of what is happening online to spill back into the living room in new and different ways.

In using the term reportability, we refer to the quality that information has in regard to it being both worthy of report and its ability to be reported.

\section{From pervasive games to promoting debate}

In order to explore the issues pointed to above, we are going to draw upon the data from an ethnographic study of a managed trial called Bicker Manor $[6,24]$ that was accessible across a number of different platforms, had the character of a game, and that was designed to both inform and stimulate debate about the environmental issues. Bicker Manor was situated within a larger project that expressly sought to investigate ways in which new technology might be used to facilitate the creation of massparticipatory events [44], strongly echoing recent European missions to encourage e-participation [21].

The trial ran over a three-week period. The principal mode of engagement was designed to be via the Internet but participants could also opt to engage via SMS messages on their mobile phones or via interactive TV. The event was structured around a hypothetical family where the mother (Eve) and father (Isambard) had strongly opposed views about how to best care for the environment. Participants were asked to side with one of these two characters and then received throughout the period of the trial several daily missions to complete as well as a series of mega missions that could be undertaken over a longer period of time. All of the missions either posed questions about environmental issues or asked participants to undertake actions that would demonstrate their attentiveness to the environment. Basic responses could be made via any of the platforms, but participants were also regularly asked to upload media in the form of either photographs or video files, which could only easily be accomplished online. Scores were allocated for completed missions and a running tally kept for the two sides throughout the trial. 
Overall management of the game was represented as being from the point of view of the family's daughter, Michaela. Thus, questions and missions were scripted as coming from either Eve or Isambard, but overall administrative messages were written as though they had come from Michaela instead. Facilities were also provided for participants to 'make friends' with other participants so that they could share certain information amongst themselves.

Participants in the trial were invited members of the public rather than it being open access, but a wide variety of people from different backgrounds and with different patterns of habitation were involved, with the intention being to make it as close in character to an open event as possible.

Ethnographic observation of the trial was conducted throughout the 3 weeks of its duration. The observations focused upon capturing in situ engagement through the use of 3 complementary strategies. A full record was kept of the engagement of 2 participants from the same family to facilitate the keeping of an ongoing record of how participation was managed in the context of everyday life. Three households were visited to capture both in situ engagement with the trial and a set of wider reflections about the trial, how engagement was coordinated with everyday household routines, and how engagement was located within the technological organisation of the household. During the course of the trial, a further 2 participants were interviewed over the telephone to discuss similar issues. Households studied included families with children, couples, and single people, with participants being of a variety of ages from 18 upwards involved in both professional and manual occupations. Notionally at least, participants in Bicker Manor could be asked to engage at home, at work, in social settings, or in transit from one location to another. Four of the households studied had access to interactive TV but only 1 tried to use it regularly for the game. All households had Internet access, and for most, this proved to be the primary platform. One participant used mobile phone-based SMS messaging throughout the course of the trial as the principal form of engagement. All of the study subjects straddled at least 2 of the 3 platforms, and none of them used just one platform exclusively.

The rationale underlying the ethnographic study of Bicker Manor was a wish to capture the in situ experience of participating, together with the ways in which participation was interwoven with everyday life. In keeping with this rationale, the analytic approach to the data from Bicker Manor was ethnomethodological [25]. In other words we sought to uncover the social organisation at work in each particular setting and to understand the methods or practices adopted by people that serve to render that organisation both orderly and visible. The particular benefit of this approach with regard to our interests here is that it brings into view how people account for their engagement and this goes to the heart of how debate might be fostered or impeded by different kinds of designs.

Against these ethnographic materials, we are going to contrast the findings from a previous ethnographic study of how players managed the playing of a multiplayer pervasive game, in the context of their ordinary everyday lives [3]. It is important to stress that this contrasting event had nothing to do with e-debate. It is included here because it is an apposite example of the kinds of mechanisms that exist that can prompt people to discuss the content of materials they receive on their phones. The importance of this factor will shortly apparent.

The game in question is called Day of The Figurines, see [7] a multiplayer board game that is played by sending and receiving text messages on a mobile phone. It follows $24 \mathrm{~h}$ in the life of a small virtual town. The $24 \mathrm{~h}$ of virtual game time is mapped onto 24 days of real time. As the game runs throughout the majority of each day, people playing the game may receive messages from the game and interact with it in any situation: at work, at home, out and about, perhaps whilst travelling. This being the case, the game is capable of prompting a particularly rich and diverse range of possible situations where players might have to account for their actions to other people around them. The game was studied in a similar manner to Bicker Manor, and the materials gathered constitute a rich set of data about a wide variety of ways in which players, amidst their families, friends and work colleagues, at home, at work, whilst travelling, and out socialising, all found ordinary ways in which to manage the accountable character of the gameplay.

\section{Engagement and reportability}

In this part of the paper, we will focus upon reportability, with particular emphasis upon two aspects: (a) the interactional circumstances that provide for reports to happen, and (b) the ways in which reports can be prompted (i.e. how things come to be seen as reportable). As we will see, engagement and reportability are tightly intertwined. Our underlying concern with reportability is that, without the reports of some kind, be they invited or offered, the content with which one is engaging never has a chance to become a topic of conversation, discussion, and debate. This being the case, the materials being provided and the question being posed will remain the province solely of those directly participating through the technology. We take this to be a severe limitation and contrary to the notion of e-debate, which should trigger participation, not constrain it. 


\subsection{The situated accountability of reports}

\subsubsection{Restrictions on reportability}

A first thing to note is that reporting - that is, recounting to others something that has happened or some piece of information that has come your way-is not a thing that can just happen at any time and in any way and on any grounds in people's interactions. First of all, you have to position a report right in some ongoing course of talk. Not just anything can stand as an opener for conversation [43], and if the report lacks credibility on that score, it must be introduced instead during ongoing talk. For that to happen, its relevance to prior utterances has to be made clear somehow [43]. Nor can reports have just any form. They have to be somehow intelligible to those with whom one is interacting, in other words they have to be recipient designed, which can sometimes mean saying a whole lot more, but just as often a whole lot less. Furthermore, a report, even as a relevant part of ongoing conversation must contain something that makes it evidently report-worthy, otherwise one's interlocutors can reasonably ask 'And why are you telling me this?'. One has to make a point of reporting, but to do so the 'point' must be visible. The actual activity of reporting must be easily accounted for.

So one item in Bicker Manor that did end up being reported was a claim that Starbucks wastes 23 million litres of water a day by having its taps left running across all of its outlets. The observed report happened several weeks after the conclusion of the trial as part of a broader conversation about waste. Kafka27 and Norc, who both lived in the same house, did also briefly ask one another how they had responded to specific questions in the game. For instance, one question asked

'What would you rather do to make you greener? A)

Wear a jumper knitted by Gran B) Share a bath C)

Give up flying for a year D) Don't drive for a month.

Isambard' 29/11/08

However, in this case, Norc just wanted to see what kafka27 had replied because he himself had responded 'Share a bath' and had found it vaguely amusing. None of the content was discussed between Norc and kafka27 at all with regard to how it presented environmental issues.

This can be compared to a number of interchanges between two players in the same household in 'Day Of The Figurines'. On one occasion, Celtic24, whilst passing his father on the stairs, announced 'I've just won a goldfish'. On another occasion, he told his father 'I'm on the point of passing out', whilst his father was moved to report 'I've beaten my way into the police station with a goldfish'. On all of the occasions when these kinds of interchanges happened, they were making direct reference to unfolding events and situations in the game.
More importantly, this did not stop at interchanges between players. At one point, Celtic24 was standing in the kitchen talking to his mother when a message came in on his phone. He inspected the message and then said to his mother:

Two lovers have been found dead in the cemetery

On another occasion, he made a point of telling his brother and sister he was walking around with a crowbar.

A particularly significant feature of the above interchange is how it demonstrates an orientation to what might count as newsworthy. In this case, Celtic24 had already been in conversation with his mother when the message came in. Nonetheless, he was able to announce the death of the lovers as a new topic of conversation. There are two things worth noticing about this. First of all, teenagers engage in the exchange of text messages in the company of their parents all the time and Celtic 24 was no exception to this. They very quickly cease to report the content of every message they receive; indeed, they would often be embarrassed to do so (and sometimes make an effort to disguise their texting as a consequence). So the message about the lovers counts, without reflection, as something that can be immediately reported to one's parent. The fact that two lovers have been found dead in the cemetery is itself, of course, something one might consider to be significant news but it is not like Celtic24's mother takes this to be 'real' news about events in the local village or anything. Instead, it is oriented as a part of the ongoing game he is involved in, hence her subsequent remark:

Oh really? Are you going to eat anything today?

So (a) it is okay to report things about the game, and (b) the reports are understood to be relating to the game and are treated accordingly, rather than as matters that should suspend the ordinary course of life. The other thing we can see about this is that the interruption of the son/mother interaction by an incoming message was itself accountable in some way. The very fact that Celtic24 was bothered to pull his phone out of his pocket and check the incoming text whilst in the midst of a conversation made it open to report. Routine interchanges with friends might have led to the incoming message being heard. But its priority would have been different. An important part of Day of The Figurines was the way participants oriented to incoming messages as something to be attended to more or less immediately, and this is something we shall be going on to discuss shortly.

In relation to the matter of newsworthiness, we observed earlier how Celtic24 reported to his father on the stairs that he had just won a goldfish. The important feature of this is not just its reportability but how it can be presented as a very first utterance. It differs from the situation where he 
has witnessably just received a message and read it. Yet he can say this to his father out of the blue. In other words, it has 'first-topic status' [37]. But who might such matters as this count as first-topic candidates for? His father is a coplayer with a similar orientation to the unfolding course of play so, for him, it is readily accountable. For anyone else, Celtic24 would have been obliged to explain the remark more fully, so a further subtlety here is the way Day Of The Figurines provided for co-report amongst participants, making its absence in Bicker Manor all the more significant. In fact, this is rendered more ironic still by the provision within Bicker Manor, using social software as an inspiration, of a mechanism whereby participants could 'befriend' one another and exchange comments about the game. Yet Norc and kafka27 never managed to make friends with one another even though they occupied the same household, meaning that the status of their participation relied solely upon their offering up verbal reports.

The contrast here could not be much stronger. As we have discussed in the previous work (see [43]), players routinely oriented to their interactions with the game during Day Of The Figurines as accountable to others around them. This meant that at any moment they engaged with the game in the company of others, they understood that they might need to report on what it was they were doing, even to the point of content. One player, Tog, for instance, reported several occasions where he did not respond to potentially flirtatious messages from other players whilst sat at home texting in the company of his wife. In Bicker Manor, any kind of reporting about the game to others was very restricted indeed. The routine receipt of questions and responses from the game lacked the kind of newsworthiness that might give them first-topic status and they were almost never taken as a prompt for report, for reasons we shall be discussing shortly. There are, however, some important and telling exceptions to this.

Norc goes to show a plastic bottle from the recycling to his wife in the kitchen. She is doing baking with their youngest daughter. He waits whilst she tips flour into the scales and his daughter tells me they are baking but burnt the sugar in the oven, then says to his wife, showing her the bottle: What do you think that means?-God, I don't know-I have just been sent a multiple-choice question$\mathrm{Oh}$, right-with four options. There are only two possibilities I reckon. The number of times it has been recycled, or the amount of oil in the plastic. Or it could be the type of plastic I suppose.-Don't know-I think it must be the number of times recycled. If it was the type of plastic, it would be a larger number-Well the oil doesn't sound likely. And the type of plastic, well, there's loads of different types of plastic-Yeah, that is what I was thinking. That would make the number longer-It must be the number of times-Yes, that is what I reckon.
Later, Norc finds out the answer-When he goes down for lunch a little later, he says 'It was the type of plastic'So there's just two types of plastic then?-It would seem so

There are several things to notice about this. First of all, to show this kind of interest in the contents of one's recycling bag is really quite a strange thing to do. People do not typically rummage around in their rubbish in this way, let alone then carry it through to their kitchen to have a discussion about it. That it requires an account of some kind is evident and several of the tasks proposed by Bicker Manor were similarly visible and accountable to other members of the household. At the same time, the only account Norc needs to give for his actions is 'I've just been sent a multiple-choice question'. He sees no need to explain things further, just where he might have been sent a multiple-choice question from being treated as obvious. Nor does his wife probe the matter further, confirming his assumption that she understands it to be a part of the game. Alongside of this, and importantly for the larger objectives underlying Bicker Manor, the episode facilitates a discussion about the content, and subsequently, something is learnt that is actively shared between them. So clearly, online events such as Bicker Manor can be mutually oriented to, reportable, discursive resources amongst larger cohorts such as households given the right kinds of circumstances. So why did Bicker Manor only occasionally manage to produce this kind of effect?

The experience of the game offers others using the system the ability to see what is being reported. Other projects such as Tidy Street [47] and the Neighbourhood Scoreboard [35] take a different approach by siting large, situated public displays within a community setting, this in itself draws attention to the data represented and they argue that this encourages community participation and debate, in this case around environmental topics. Building on this kind of research may prove advantageous for systems such as Bicker Manor in numerous ways, such as promoting the system, happen chance discovery of facts, and encouraging non-technologically mediated, face-to-face community discussions. It would even be possible to move the displays onto sites that have a different level of impact within the community, or to encourage flash mobbing in these sites so that physical activities could take place with other members of one's community. Key to understanding the impact of such settings would be understanding and developing such systems in real-world settings, sometimes referred to as in the 'wild' [15].

\subsection{Prompts to report}

\subsubsection{Invitations and callings to account}

A standard prompt to report is to find oneself in some circumstance where one is invited to explain one's actions 
or where one sees oneself as accountable for them in some way. As a consequence of its capacity to breach a range of social situations, Day of The Figurines was regularly a source of both disruption and account. We discuss this in some considerable detail in the previous work [49]. What makes an important distinction between Day Of The Figurines and Bicker Manor is the fact that for the majority of each day throughout that running of the event, Day of The Figurines could result in people receiving a text message at pretty well any time. They were therefore obliged to manage their interactions with the game in ad hoc ways. This meant that they often found themselves in situations where people either noticed their interaction with their mobile phone and expected some kind explanation, or else they felt it was incumbent upon them to account for what they were doing in some way. The management of interaction with Bicker Manor proceeded in a very different way. This resulted in the participants positioning their interactions in ways that were tailored to their existing routines, rather than having these routines disrupted. As people do not typically organise their affairs so that they have to continually account for them, Bicker Manor became, unsurprisingly, elided into a range of unremarkable activities [48]. In the following materials, we look at some of the ways in which this management occurred.

\subsubsection{Occasioning and opportunity}

An important finding of the ethnographic study of Bicker Manor was that the very structure of the game and people's interactions with it served to mitigate against the occasioning of accounts or the very opportunity or reason to report. This carries further implications for how far the game was capable of engaging groups of people in debate about the environmental issues it was raising. One of the important features of the structure was that the timing and criticality of the messages facilitated the easy management of one's own interactions with the game, an apparently desirable outcome.

\subsubsection{Prioritisation, predictability, and time criticality}

One particular feature of Bicker Manor was that participants quickly reached a point where they could predict when missions were going to be assigned and encountered.

It is just after $10 \mathrm{am}$ and Norc is shopping at Sainsbury's. He hears a message tone on his phone but does not respond. Later on, Norc commented

'I knew it was the game, and I know I will only get one message. And it's not as if it's urgent, they have no time critical element. I figured: "I can do it any time in the day, so why do it now when it's not convenient?",

As can be seen from this extract from the notes, it did not take long to recognise an incoming message as being from the game because the messages always went out at the same time of day. A consequence of this predictability was that immediate checking of the phone when hearing messages was only a feature early on in the game. This can be contrasted with the following example:

16:12 message comes in-Even though working Norc checks straight away because he's not sure it's from the game-It's unusual to get a game message at this time

This delineates the prior observation. In this case, the phone is checked precisely because it might not be from the game but from someone else and therefore more important.

So, in Bicker Manor, once the pattern became predictable, it was easy to set messages aside saying 'oh, it's only the game' and not take them to be urgent. In Day Of The Figurines, participants nearly always checked their phones immediately, even though this meant they might have to account for doing so, and, by contrast, considered many messages to be time critical with definite outcomes for their health (in the game, that is) if they ignored them.

It is not as if there were no time-critical tasks in Bicker Manor. On the contrary, many of the missions were only listed as active missions for a certain amount of time. However, the kind of orientation participants exhibited to this is demonstrated by the following:

'Missions just drop into extra missions so you can do them anyway'

So what typically happened once a mission had timed out was that it was then posted in a players' 'Extra Missions' list, meaning that they quickly realised they could always go back and do it later. Nor did failing to complete a mission have any evident consequences beyond missing an opportunity to increase your points. However, for reasons we shall be shortly elucidating, the scoring system did not work as a strong motivation amongst the participants in Bicker Manor.

This can be compared with how time criticality was oriented to in Day of The Figurines.

The whole family are sat down to watch a film together-Tog receives a message and pulls out his phoneHaving read the message he sends back a quick response (he is currently engaged in pursuing a mission and has already received a number of texts, one of which read: $\ll$ 08:00 pm, new task: a rat faced man in a waistcoat rushes up: 'The drummer's been arrested. Find a DRUM KIT and get to the Locarno by $10 \mathrm{pm}$ to take his 
place $\gg$ )-Shortly afterwards Tog receives another message and immediately checks it and responds again-At this point Tog's wife says:

Are you watching this film or what?

A little later, another text comes in-When the sound of the incoming message is heard, the rest of the family look his way, frowning-This time, Tog does not take the phone from his pocket to look at it.

Here, it can be seen that the player was effectively instructed to cease playing by those around him, demonstrating the extent to which he had previously been prepared to give priority to the game when time was understood to be of the essence.

Priority is always a quite finely tuned affair. Where more than one thing is currently in need of doing the choices made as to which gets done first are always open to being called to account by those who have an interest in the other things being dealt with. Even though Tog ultimately lets the game drop in the above example, his manifest engagement initially demonstrates a presumption that he can easily account for his actions, e.g. by saying that if he does not do this, he might die. It takes a fairly strong reminder of his moral accountability to other things, such as participation in family film-viewing, for him to see what priorities he 'should' be seen to demonstrate.

In fact, in Bicker Manor, the relatively low priority participants could easily ascribe to the game had additional consequences. We have already outlined above how the performance of physical tasks was one of the few things that actually really did seem to facilitate the kinds of phenomena the game was designed to encourage. The trouble with physical tasks was that they took additional investment of time and effort beyond immediate interaction at the game interface, something that only happened at registration for Day Of The Figurines. Physical tasks typically demanded not only the performance of something in some other location, but the simultaneous creation of some kind of record of that activity through photographs or video. In view of the fact that the structure of the game already enabled it to be set aside in favour of other things and the missions were typically seen to be non-time critical, it was easy to account for holding off doing such tasks until a moment when one was not 'too busy', or to see such tasks as too much trouble to be worth the effort, as can be seen here:

'Mega missions are not as easy to do, coz you have to go and do things for them, and I just can't be bothered to do that'

As soon as a game moves beyond just the evident accountabilities of engagement at the interface to encroaching upon one's daily routine in other ways that will need accounting for, it is easy to see how these tasks might be oriented to as low priority. Evidently, the need to account for them is a powerful drive to reportability and further interaction around the kinds of issues the game is designed to expose. However, to accomplish this effectively, the game also needs to provide the kind of structure and engagement mechanisms that will enable participants to locate adequate grounds for its prioritisation over the ordinary requirements of everyday living. One such ground that can be used is competition that one will suffer negative outcomes if you hold this off to another moment, but Bicker Manor was not constructed to support such motivations.

\subsubsection{Competition as a trigger}

As can be seen above, the sense of competition in Bicker Manor was rather undermined by the fact that supposedly time-critical missions just slipped into the category of extra missions and could therefore be completed on another occasion. Indeed, for many players, going to extra missions became a routine way of doing them. The other mechanism for competition that was apparently provided was scoring. Each mission had a certain number of points allocated to it, and players were able to see their tally whenever they went to their own page on the Website. This was somewhat undermined by the fact that a bug in the system meant that some players discovered they could go back and do the same mission multiple times, thereby boosting their score enormously. However, the more important concern here is revealed by the following comment:

'You don't see any other points registered on the page apart from Isambard's and Eve's which are huge numbers, so I just don't feel motivated to try and compete'

Amassing points is ultimately pretty meaningless unless one has some sense of how that might compare to others who are participating. In this case, all that was available was the gross tally of all the players associated with Isambard versus those associated with Eve, and players found this to be of little interest. What they did crave was a sense of personal competition but this was not given to them, leading a number of players to question whether it was a game at all. Indeed, one player commented that it was more like filling in a questionnaire.

Obviously, there is no intrinsic need for online events that are designed to encourage debate to have a game-like structure or to encourage competition. However, what does matter is that the event provides some mechanism, whereby it becomes reportable to those around you. Where competition is a potential element, it provides players with a reason to orient to their interactions with it as being of a 
certain accountable priority. Thus, one can find them seeing adequate grounds in it for engaging with it at times when it can potentially impact upon others around them. This in turn makes it likely that engagement will be called to account from time to time, and that is at least one way in which forums for report and discussion can be created.

\subsubsection{The routinisation of engagement and its resulting 'invisibility'}

There is one other significant way in which the structure of Bicker Manor served to limit its scope for reportability. We have already discussed the fact that players received messages from the game at enormously predictable times. It was also the case that messages were usually only sent to players once a day. For players, using computers to engage this had an almost inevitable consequence. The mechanism worked in such a way that the usual way for those playing on computers to receive a message was via their email. In that case, as the following remarks make clear, what happened was that the messages were discovered and treated as a routine part of people working through their email inboxes, potentially during work time:

'I've gone online almost exclusively when I've been prompted... When I've had an email telling me there's a new mission and if it's been convenient I've gone straight online... Almost always during the day when I've been at work'

Email interaction can occur throughout the day, and many working people do keep their email applications open so that incoming messages can be noticed as they are received. However, when there's only one mail a day, and what is more, at more or less the same time every day, the treatment of that mail almost inevitably becomes routinised as a feature of the larger sequence of dealing with emails. This means that engagement with the game managed to blend wholly into other activities, making it neither noticeable to others nor open to report or remark.

Even for those engaging via mobile phones, the visibility to others was really very low. A part of what happened in Day Of The Figurines was that the very frequency and oddness of timing of incoming messages tended to make them noticeable and accountable to other people, as the following reveals:

'For the first few days I was playing text messages coming in during the evening were almost always noticed. In other words people would look at me whenever the phone made a sound and then I'd have to say something like "it's okay, it's just the game"'.

However, in Bicker Manor, what happened most often was that one text message was received each day. It was at a regular time and had only that one chance to be noticed and made reportable to others. Any other messages from the game were so rare that they managed to blend into the potential receipt of any text message for most players. This alone made them pretty well unremarkable and to all intents and purposes invisible to other people. Why comment suddenly upon the fact that someone has received a text message when they get text message from time to time anyway? This was made even more the case by the fact that few players oriented to the incoming message as anything they should be taking a special interest in or dealing with immediately. Indeed, the latter point is also significant because the orientation to interaction with the game through response to messages as something postponable meant that players mostly held off responding until moments when they were doing nothing much else, as the following reveals:

15:02 Norc hears another message coming in on the phone. He is online booking a hotel at the time so he leaves looking for now. After this he gets involved in making arrangements for work the following week.

17:04 Norc finally gets a chance to check his phone

This only served to make it even less likely that their interactions with the game would be visible and accountable to others.

\subsubsection{Engagement as a methodical outcome}

What we have been outlining in the above materials are the ways in which engagement is not just something that happens when presented with materials that might be considered inspiring, challenging, or controversial. Instead, engagement is a methodical accomplishment that turns upon certain mechanisms that have to be realised in situationally nuanced ways. This is just as much the case whether the materials are well or poorly realised. Clearly, there are ways in which one might argue that engagement in Bicker Manor might have been better if the content had been improved. Certainly, some players did complain that the content was not particularly motivating or memorable. However, this rather misses the point. If that was the only story here, this paper would be of little value. Issues of content are easily remedied in further iterations, and this was, after all, just an initial trial, not a finished product. Nor is there much about that to interest designers. What we have been at pains to present here are the ways in which it was the actual structuring of interactions between players and the system that most significantly undermined the scope for the game to promote an engagement with the game that was reportable and implicative for debate. Systematically, these features were as follows: 
- An absence of recountability as an unfolding series of events or as news

- A lack of mechanisms to provide for interaction with the game that would be open to explanation and account

- A lack of mechanisms to provide for the prioritisation of the game in situated interaction in ways that would make it visible and accountable

Some of the things that fed into this were as follows:

- A limited number of interactions with the game

- A predictable timing and frequency of interactions with the game

- The lack of implicativeness of messages for immediate response

- The lack of accountable grounds for immediate response such as competition

All of which led to an engagement with the game that was largely routinised and non-implicative for wider interactions.

Most particularly, in view of what we said in the introduction regarding the move away from co-situated family viewing, one potential problem with Bicker Manor was that people gravitated to what might be called an 'inappropriate' platform. In other words, they all preferred to manage their interactions on their PCs, even when they were presented with alternative platforms. It was the use of this platform, largely out of the sight and company of others, which particularly led to the absence of report and the routinisation of engagement.

\section{Designing for reportability}

Clearly, as the above materials indicate, one potential consequence of pushing mechanisms for the exposure of issues and the facilitation of debate to the Internet is that it may actually serve to reduce the opportunities for debate amongst certain cohorts, despite its best intentions to the contrary. Nor are these insignificant cohorts. It is exactly the cohorts with whom people are most closely related that are most likely to be unaware of the content of their e-participation.

There are three key consequences that can be derived from the above findings: (1) online engagement is easily de-prioritised and routinised to a point of invisibility; (2) online engagement lacks the prompts to reportability that might make the debate and its content more visible; (3) most critically, it would appear that, for the support of mechanisms of natural co-present interaction around topics of debate, conventional computer-based access to online resources may amount to the use of an inappropriate platform.
We now want to move on to considering how these three issues might be tackled from a design perspective. In Day Of The Figurines, reporting and accounting to others is an incidental feature of the gameplay, arising from that fact that messages can arrive at unpredictable moments, in unpredictable situations, through the means of a highly visible and to-hand technology. Reporting in this case is a method for handling the disruption of cohorts. The question we want to pose here is, are there ways in which reportability can be designed in where the goal is to directly encourage discussion and debate?

In response to this, we can observe several tactics that might be adopted.

The first of these relates to how the content of the game, even if it is invisible at the point of delivery, can encourage participants to engage in actions that are actually anything but invisible. In this respect, we might note that Bicker Manor was not by any means a total failure. On a number of occasions, as with the recycling issue, participants were asked to do things that directly drew comment. For instance, Norc found himself taking photographs of a sandwich on one occasion and getting his son to video him tossing waste on the compost heap on another. Neither the preparation of a sandwich nor the tossing out of compost were particularly remarkable events in their own right, but the capturing of a record immediately drew the attention of other members of the family. Other participants found themselves building models out of waste materials, and sticking labels on kettles that had similar consequences. So asking people to do 'remarkable' physical activities is clearly one strategy for encouraging the articulation of accounts [42]. This can be tied to other documented design activities already in the literature where highly visible action that would draw comment and discussion was a deliberately designed in feature of people's interactions with a system. Examples here include Jane McGonigal's Top Secret Dance Off where she has people directly challenge the conventional framing of experiences by videoing themselves dancing in public spaces such as road crossings, upload these and then have other people rate them [50]. Another example is The Go Game. In this case, a management training game company has created highly visible 'interactive events and scavenger hunts for groups of 3-10,000 players anywhere in the world'. [45]. In the game Hot Potato, Niemi et al. [37] had players directly challenge ordinary orientations to strangers by involving unwitting bystanders as 'mules' to carry hot potatoes for them. This worked by detecting the Bluetooth ID of a passerby so that you could then associate them with the potato object in the game and where you then had to keep in range by following the bystander. In another game, Can $U$ See $\mathrm{Me}$ Now? [4], the runners involved in a large-scale game of hide and seek organised on a city's streets became publicly 
visible through their unusual garb and the very ways in which they were obliged to run around. Further examples where people might be obliged to dress up, do strange things, and so on, abound [11].

The third issue we noted above regarding the character of the platform has, in a sense, got to be tackled before the issue of routine prompts to reportability can be properly dealt with. The pushing of people to personal, low-visibility interactions with devices, away from the main centres of co-present interaction in an environment, goes to the heart of what we said in the introduction regarding the shift in potential vehicles for debate away from the family viewing of television. Ironically, a more promising feature of Bicker Manor here could have been the use of interactive TV. Through interactive TV, the content of the game might have been brought directly to mutually available TV displays in people's living rooms. However, another significant finding of the study was the fact that people who have bought systems capable of interactive TV actually mostly use them for on-demand TV, not interactive TV. In the trial, a combination of their unfamiliarity with the interaction mechanism and extremely slow loading speeds drove people quickly to other platforms.

The most direct response to the challenge of finding the right platform is to drive interaction to a mobile platform, similar in structure to that used in Day Of The Figurines. What we saw in Day Of The Figurines was its capacity to interrupt and draw attention to itself in a variety of settings, often in the company of friends and family. One promising route towards encouraging debate within such cohorts is to ensure challenging issues are introduced into settings where families and friends are congregated together, and in such a way that they do become a potential topic of conversation. In this case, a mobile platform would appear to be more productive than something based on a computer because mobile phones travel around into settings where interactions with families and friends are likely to occur, whereas people are often isolated when using their PCs. Nor are they necessarily with their PCs throughout the day. Furthermore, engagement with a PC is not open to the same kind of reportability as receiving a message on your phone. How many times do people, when they notice other people using a PC, ask them just what they are doing? (unless it is something visibly dynamic such as watching a video, or whatever)? The potential of mobile platforms to encourage the right kinds of interaction is further revealed in recent discussions of social iTV systems where video content is delivered directly to mobile phones in social situations [38, 49].

Once a mobile platform is present, handling the second issue pointed to above of creating prompts to reportability becomes more straightforward. There is a deep irony in the fact that many designers when creating games such as Bicker
Manor actively seek to make experiences that gracefully interweave with people's ordinary everyday lives. This was an important feature of the Bicker Manor design discussions. However, the very effort of making the game manageable in time facilitated the back grounding of the game to a point where it was no longer remarkable. The clear implication here is that there is a need to make interactions unpredictable so that some kind of reporting will inevitably have to happen from time to time. However, it would also seem advisable that design here be a little less crude than just the random generation of messages. One thing worth considering is the extent to which we might be able to predict opportune moments. The challenge here would be to create mobile experiences that are framed to generate debate by disrupting targeted settings. This would necessitate some form of detection of the kinds of cohorts people are currently engaging with (e.g. family and friends rather than a lecture theatre and a train with a bunch of strangers). Ubiquitous context aware systems may be able to help here, though it is doubtful that they are currently capable of making cohort judgments of this kind of sophistication as some may have initially envisaged [52]. Clearly, there are limits to how far one should try to be disruptive. A frequency of contact that began to register as spam would not be a good result. Nor should the disturbances and required reports be matters of embarrassment or annoyance. In our prior work, we discuss how a part of the requirement for designing for instances of disruption is a provision for supporting the local management of that disruption. In other words, there is a need to support the practices of reporting that already exist in interaction. Often, this turns upon making the grounds of disturbance visible [37, 51].

The use of mobile technologies in many respects is an obvious evolution of the system, but as we have seen it is not the move to the mobile system that is problematic, but dealing with the sociality of mobile use within co-located settings. If we examine the contemporary research in this area, there are examples such as Ames's [2] examination of techno social use of mobile phones, including the role that social hierarchies and relationships play in the 'accepted' use of the device in co-located settings, which has implications for long-term use, whereas Leong and Wright [31] take a position that suggests that the use of mobile technologies for music-based practices, in group-settings, can engender participatory engagement between co-located users and that new social practices can emerge from this. In regard to these stances, when developing a mobile platform for the game, we would need to be sure that mechanisms were in place that allowed any users to adjust their preferred level of interruption and define situations where this would be allowed.

Clearly, not all parts of the solution we are putting forward in this paper are equally tractable. Some matters, 
such as focusing on a mobile platform and asking people to do things that are readily visible, are not necessarily difficult in themselves. However, a critical component of how opportunities for debate might arise is the rendering of one's interactions with content reportable. Designing for reportability therefore requires careful consideration of how to structure events so that they can intercept with people's lives in ways that will not simply disrupt but rather feed into reports and accounts in ways that are productive of further discussion. In many respects, this is complicated, being able to pinpoint the places in one's daily routine where disruption is minimal, but where the system can identify maximal impact in order to deliver a report (in order to engender activity) is difficult and may also mean that there would need to be a degree of tailoring for each individual user. Fogg [23], in his work on persuasion, writes, 'timing-is often the missing element in behaviour change. In fact, this element is so important the ancient Greeks had a name for it: kairos - the opportune moment to persuade'. With this in mind, we would argue that due to the importance of this issue, it should emerge from the research as a key area for future investigation that could involve sensor-based systems as part of the technical infrastructure of the game, as in other pervasive experiences, such as Them and Us [11].

\section{Conclusion}

In this paper, we have used a detailed analysis of ethnographic materials drawn from two distinct events to delineate some important challenges to how e-participation is currently structured. In our view, the issues are not insurmountable but rather require designers to reflect carefully upon the kinds of mechanisms and platforms they use to encourage online participation. Our intent is not one of harking back to some golden (and possibly mythical) age of everyone debating weighty matters around their televisions. Rather, we would wish the enterprise of e-participation to more fully realise its potential through close attention to how the actual workings of everyday interaction may currently be thwarting some of its objectives. Recognition of this and design founded upon that recognition may well lead to whole new forms of e-participation that are neither a return to old forms of media consumption nor the current kinds of interactions taking place online, but rather something that takes inspiration from both of them.

Acknowledgments We gratefully acknowledge the support of the UK Technology Strategy Board and EPSRC funded project Participate (http://193.113.58.250/index.html) and the European Union funded iPerG project (www.pervasive-gaming.org). This work evolves from our previous publications in this area $[10,13,24]$.
Open Access This article is distributed under the terms of the Creative Commons Attribution License which permits any use, distribution, and reproduction in any medium, provided the original author(s) and the source are credited.

\section{References}

1. A2D (access2democracy.org). http://www.access2democracy. org/

2. Ames MG (2013) Managing mobile multitasking: the culture of iPhones on stanford campus. In: Proceedings of the Conference on Computer Supported Cooperative Work (CSCW 2013). San Antonio, Texas, USA: ACM

3. Benford S, Crabtree A, Reeves S, Flintham M, Drozd A, Sheridan J, Dix A (2006) "The frame of the game: blurring the boundary between fiction and reality in mobile experiences", SIGCHI Conference on Human Factors in Computing Systems (CHI 2006), April 22-27, Montreal:Quebec, ACM 2006

4. Benford S, Crabtree A, Flintham M, Drozd A, Anastasi R, Paxton M, Nick Tandavanitj N, Adams M, Row-Farr J (2006) 'Can you see me now?' ACM Trans. Comput Hum Interact 13(1):100-133

5. Berker T, Hartmann M, Punie Y, Ward KJ (2006) Domestication of media and technology. OUP, London

6. Bicker Manor. http://www.bickermanor.com/web/bicker-manor. html

7. Blast Theory. http://www.blasttheory.co.uk/

8. Buckingham D (1987) Public secrets: EastEnders and its audience. BFI Books, UK

9. Chamberlain A, Griffiths C (2013) Moths at midnight: design implications for supporting ecology-focused citizen science. In: Proceedings of the 12th International Conference on Mobile and Ubiquitous Multimedia (MUM2013), Luleå, Sweden, Dec 2-5, ACM Press

10. Chamberlain, A. et al (2014) 'Understanding the design of mass participatory pervasive computing systems for environmental campaigns', Personal and ubiquitous computing journal, Springer:ACM Library

11. Chamberlain A, Martínez Reyes F, Jacobs R, Watkins M, Shackford R (2013) Them and us: an indoor pervasive gaming experience, entertainment computing journal. Elsevier, Amsterdam

12. Chamberlain A. et al. 'Locating Experience: touring a pervasive performance', Personal Ubiquitous Computing Journal, Volume 15 Number 7, Springer Verlag

13. Chamberlain A et al. (2013) Participate: pervasive Computing for Environmental Campaigns. In: Proceedings of the Human Computer Interaction International (HCII), Springer-Verlag

14. Council of Europe, Committee of Ministers (2009) Recommendation $\mathrm{CM} / \operatorname{Rec}$ (2009) 1 of the Committee of Ministers to member states on electronic democracy (e-democracy)

15. Crabtree A. Chamberlain A. Grinter R. Jones M. Rodden T, Rogers Y. (eds.) (2013) Special issue on "The Turn to the Wild" with authored introduction, ACM Trans Comp Hum Interaction ToCHI 20(3), 13:1-13:4

16. Debatepedia, http://wiki.idebate.org/index.php/Welcome_to_ Debatepedia\%21

17. DoWire.Org (Democracies Online). http://www.dowire.org/

18. Dutton W, Rogers E, Jun S (1987) Diffusion and social impacts of personal computers, Commun Res 14(2):219-250

19. eDebate.com, http://www.edebate.com/

20. E-Democracy.org (2006) Presidential E-Debate-Minnesota Gubernatorial E-Debate. http://www.e-democracy.org/e-debates/

21. E-Democracy.org, http://pages.e-democracy.org/About 
22. European Commission, http://ec.europa.eu/information_society/ activities/egovernment/policy/eparticipation/index_en.htm

23. Fogg B (2002) Persuasive technology: using computers to change what we think and do. Morgan Kaufmann, San Francisco

24. Flintham M, Price D, Benford S, Chamberlain A et al. 'Bicker Manor: a cross-media environmental campaign using missions'. ACE 2009-International Conference on Advances in Computer Entertainment Technology

25. Garfinkel H (1967) Studies in ethnomethodology. Prentice Hall, Englewood Cliffs

26. Geerts D, Cesar P, Bulterman D (2008) The implications of program genres for the design of social television systems. In: UXTV '08: Proceeding of the 1st international conference on Designing interactive user experiences for TV and video

27. iPlayer. http://www.bbc.co.uk/iplayer/

28. Kraut RE, Kiesler S, Boneva B, Shklovski I (In press). Examining the impact of Internet use on TV viewing: Details make a difference, in R. Kraut, M. Brynin, and S. Kiesler (Eds). Domesticating Information Technology. Oxford University Press

29. Kriplean T, Beschastnikh I, Borning A, McDonald DW, Zachry M (2009) 'Designing mediating spaces between citizens and government', Presented at the "Socially Mediating Technologies" Workshop at the ACM 2009 SIGCHI Conference on Human Factors in Computing Systems (CHI'09)

30. Lally E (2002) At home with computers, Berg

31. Leong TW, Wright PC Revisiting social practices surrounding music. In: Proceedings of the 2013 ACM annual conference on Human factors in computing systems, 2013. ACM, pp 951-960

32. Livingstone S, Lunt P (1994) Talk on television: audience participation and public debate. Routledge, London

33. Macintosh A (2006) eParticipation in policy-making: the research and the challenges. In: Cunningham P, Cunningham M (eds) Exploiting the knowledge economy issues, applications, case studies. IOS Press, Amsterdam

34. McGonigal J (2006) This might be a game: ubiquitous play and performance at the turn of the twenty-first Century, $\mathrm{PhD}$ Thesis, University of California, Berkeley

35. Moere AV, Tomitch M, Hoinkis M, Trefz E, Johanses S, Jones A (2011) Comparative feedback in the street: exposing residential energy consumption on house façades. Human-computer interaction-interact 2011. Springer
36. Morley D (2000) Home territories. Routledge, London

37. Niemi J, Sawano S, Waern A (2005) 'Involving non-players in pervasive games', Conference on Critical Computing, Aarhus, August 2005

38. O'Hara K, Mitchell AS, Vorbau A (2007) Consuming video on mobile devices. In Proceedings of CHI2007, pp 857-866

39. Park HM (2006) 'The impacts of digital government on civic engagement: a typology of information technology use. In: Proceedings of the 2006 international conference on Digital government research, pp 440-441

40. Participate Project. http://193.113.58.250/index.html

41. PEP-NET, Pan European eParticipation network. http://pep-net. $\mathrm{eu} /$

42. Rainie L, Cornfield M, Horrigan J (2005) The internet and campaign 2004. PEW Internet and American Life Project

43. Sacks H (1992) Lectures on Conversation, Volumes I \& II, Ed G Jefferson. Blackwell, Malden

44. Silverstone R (1994) Television and everyday life. Routledge, London

45. The Go Game. www.thegogame.com

46. The People Speak.org (2009) Global debates. http://www.the peoplespeak.org/activities/global-debates/about.html

47. Tidy Street [Online] (2013) Available: http://www.changeproject. info/projects.html

48. Tolmie P et al (2002) 'Unremarkable Computing', CHI'O2, NY: 23ACM, 399-406

49. Tolmie P, Crabtree A, Rodden T, Benford S (2008) Are you watching this film or what?-interruption and the juggling of cohorts. In: Proceedings of the ACM Conference on Computer Supported Cooperative Work, San Diego, Nov 2008, pp 257-266, $\mathrm{ACM}$

50. Top Secret Dance. http://topsecret.ning.com/

51. Waern A, Montola M, Stenros J (2009) The three-sixty illusion: designing for immersion in pervasive games. In: Proceedings of the 27th international conference on Human factors in computing systems, Boston, MA, USA 1549-1558

52. Weiser M (1991) 'The Computer for the 21st Century', Scientific American 